Arq. Bras. Med. Vet. Zootec., v.69, n.2, p.409-414, 2017

\title{
Melanose multicêntrica em frango de corte: relato de caso
}

\author{
[Multicentric melanosis in broiler: case report] \\ N.V. Tamiasso ${ }^{1}$, K.T. Pandolfi ${ }^{1}$, E.A. Pedrozo ${ }^{2}$, C.U. Simões ${ }^{3}$, \\ L.C. Nunes ${ }^{1}$, J.N. Boeloni ${ }^{1 *}$ \\ ${ }^{1}$ Universidade Federal do Espírito Santo - Ufes - Alegre, ES \\ ${ }^{2}$ Ministério da Agricultura, Pecuária e Abastecimento - Mapa - Vitória, ES \\ ${ }^{3}$ Cia. de Alimentos Uniaves - Castelo, ES
}

\begin{abstract}
RESUMO
Melanoblastos podem migrar de forma errática durante a embriogênese, gerando um quadro conhecido como melanose. São raros os estudos envolvendo melanose com acometimento múltiplo dos órgãos. Objetivou-se descrever um caso de melanose multicêntrica em frango de corte que gerou condenação do animal ao abate. Foram encaminhadas ao Laboratório de Patologia Animal da Universidade Federal do Espírito Santo para avaliação histopatológica amostras de diversos órgãos de uma ave de corte da linhagem Cobb de 48-49 dias de idade. Esse animal foi condenado na linha de inspeção por apresentar áreas multifocais enegrecidas. Ao exame microscópico, observou-se melanina multifocal variando de moderada a intensa quantidade em todos os órgãos acometidos com lesões enegrecidas na macroscopia. As áreas pigmentadas foram negativas para a coloração especial de azul da Prússia e não foram encontradas células neoplásicas. A pigmentação da pele em aves comercializadas no Ocidente é rara, pois a característica de pele clara foi selecionada por meio de melhoramento genético, mas pouco se sabe sobre quais mutações desencadeiam melanose nas linhagens selecionadas para não apresentar pigmentação. A ave apresentou melanose multicêntrica e tal alteração não compromete a função dos órgãos acometidos nem representa risco para a saúde humana, no entanto, devido ao aspecto macroscópico, os órgãos que apresentam tal lesão foram condenados para consumo humano.
\end{abstract}

Palavras-chave: ave, melanização, hiperpigmentação, melanina

\begin{abstract}
Melanoblasts can enter an erratic migratory pathway during embryogenesis and it creates a clinical condition known as melanosis. Studies involving melanosis in multiple organs are rare. The aim of this paper is to describe a case of multicentric melanosis in a broiler resulting in animal condemnation at slaughter. Samples from diverse organs originating from a Cobb broiler, 48-49 days of age, were sent to Laboratório de Patologia Animal from Universidade Federal do Espírito Santo for histopathological avaliation. This animal was condemned in line inspection due to multifocal black areas of pigmentation. At microcopic avaliation, multifocal melanin in moderate-intense amount in all the organs stricken with macroscopic black lesions was noted. Sections of pigmented areas were negative for Prussian Blue and no neoplasic cells were found. Pigmentation of the skin in a broiler from the Ocident is rare because the white/yellow skin was selected through genetic enhancement, but there is some data about which mutations unleash melanosis in lineages selected to not have pigmentation. The broiler had multicentric melanosis and this alteration doesn't change functional activity of the stricken organs and doesn't represent any risk for human health, but the organs with this lesion were condemned for human consumption due to their macroscopic appearance.
\end{abstract}

Keywords: chicken, melanization, hyperpigmentation, melanin

Recebido em 14 de março de 2016

Aceito em 8 de julho de 2016

*Autor para correspondência (corresponding author)

E-mail: jankerle@yahoo.com.br 


\section{INTRODUÇÃO}

Os melanoblastos, precursores dos melanócitos na vida intrauterina, migram pela crista neural de acordo com uma rota predeterminada (Dupin e Le Douarin, 2003). No entanto, durante a embriogênese, pode ocorrer migração errática dessas células e a consequência disso é uma deposição congênita excessiva de melanina em tecidos que normalmente não são pigmentados (Faraco et al., 2001), quadro esse chamado de melanose (Mcgavin e Zachary, 2007).

Apesar da melanose congênita não trazer prejuízos à função do tecido acometido, quando se trata de animais de abate, tal alteração é indesejada porque gera condenação em matadouro-frigorífico (Mcgavin e Zachary, 2007). A carcaça ou a víscera que apresentarem melanose localizada devem ser parcialmente condenadas, enquanto a carcaça ou as vísceras acometidas por melanose generalizada devem ser totalmente condenadas (FAO/OMS, 1994, citado por Teixeira et al., 2013). Por este motivo, a pigmentação foi uma característica removida das aves comerciais por meio de seleção genética, sendo as aves brancas ou amarelas selecionadas por atender as preferências do mercado (Crespo e Pizarro, 2006).

Mesmo com o melhoramento genético realizado nas linhagens comerciais, por vezes os médicos veterinários responsáveis pela inspeção em matadouros-frigoríficos se deparam com carcaças e vísceras apresentando pontos irregulares, marrons a enegrecidos, sem alteração em textura, consistência ou forma, caracterizados por melanose, e tal situação leva à condenação do animal (Crespo e Pizarro, 2006). O mais comum é encontrar apenas um tecido acometido, sendo menos frequente a associação da lesão em dois ou mais órgãos (Teixeira et al., 2013).

São raros os estudos envolvendo melanose com acometimento múltiplo dos órgãos e verificou-se que não há nenhum relato prévio de melanose multicêntrica em ave de linhagem comercial no
Brasil. Assim, objetivou-se descrever um caso de melanose multicêntrica em frango de corte que gerou condenação do animal ao abate.

\section{CASUÍSTICA}

Foram encaminhadas ao Laboratório de Patologia Animal da Universidade Federal do Espírito Santo para avaliação histopatológica amostras de fígado, coração, pulmões, baço, cloaca, rins, divertículo, proventrículo, pele, intestinos delgado e grosso, inglúvio, moela e músculo peitoral de uma ave de corte da espécie Gallus domesticus, linhagem Cobb, de 48-49 dias de idade, condenada na linha de inspeção SIF 957 no matadouro-frigorífico localizado em Castelo, ES. O material foi coletado, fixado em formalina $10 \%$ tamponada e enviado ao laboratório pelo fiscal federal responsável pelo serviço de inspeção. Posteriormente, os tecidos foram processados pelo método rotineiro de inclusão em parafina, seccionados em $4 \mu \mathrm{m}$ e corados pela hematoxilina e eosina e pelo azul da prússia.

O histórico relatava que a ave foi condenada por apresentar áreas multifocais enegrecidas, que variavam de 0,1 centímetros de diâmetro até manchas maiores que atingiam toda a pele, os músculos estriados esqueléticos, a moela, o proventrículo, o inglúvio, os intestinos delgado e grosso, o peritônio parietal e o coração. A carcaça estava dentro dos padrões de normalidade conforme o lote abatido, com peso aproximado de 2,5 quilos. Essa foi a primeira vez que o matadouro-frigorífico em questão identificou esse tipo de alteração.

Ao exame macroscópico, os tecidos apresentavam manchas enegrecidas multifocais na pele, na musculatura peitoral, nas serosas dos intestinos delgado e grosso, na moela (Fig. 1A, 1B e 1C), na bursa de Fabricius, no divertículo, no inglúvio, nos pulmões e no proventrículo. No coração, havia manchas enegrecidas multifocais a coalescentes em intensa quantidade (Fig. 1D). 

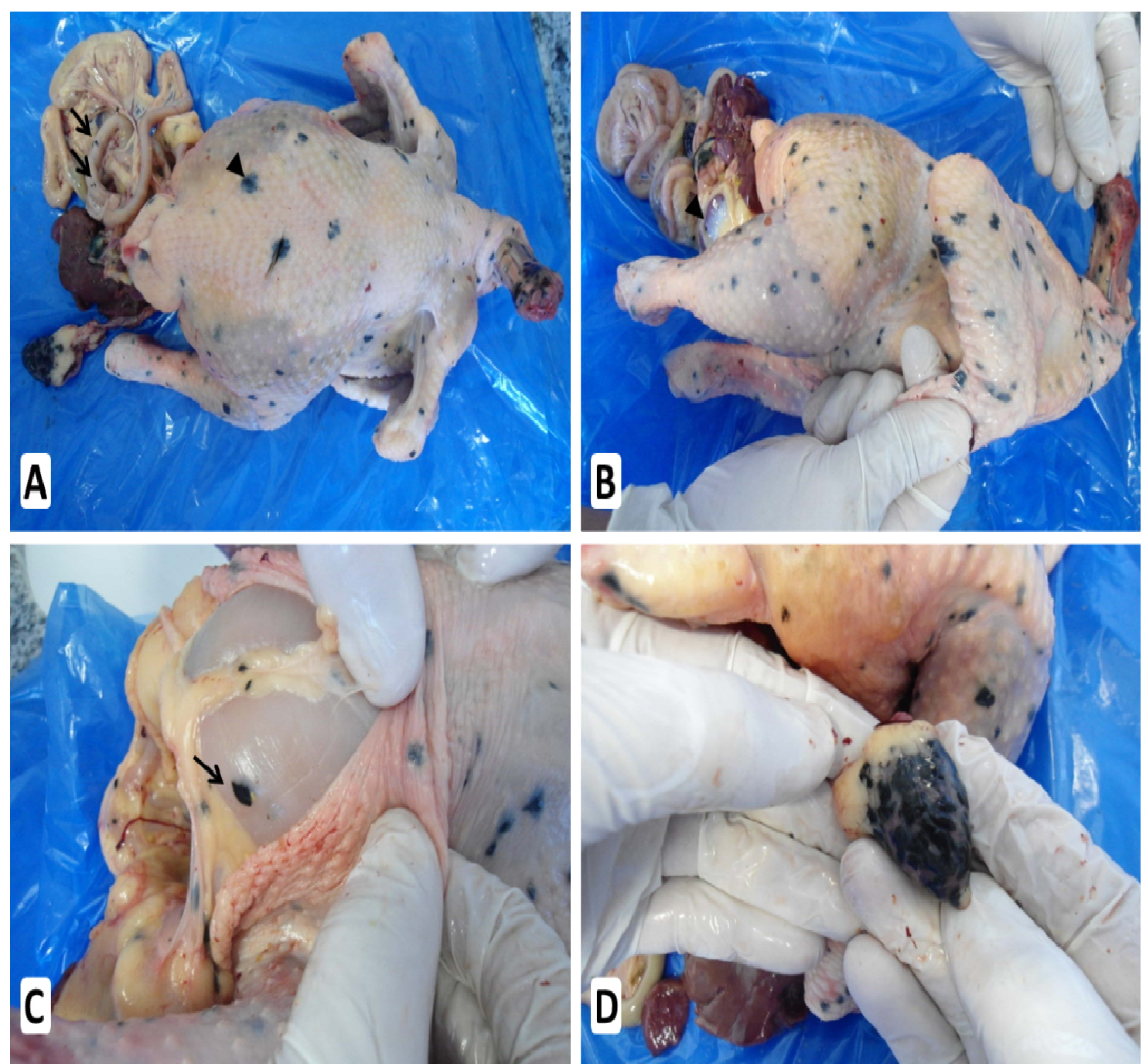

Figura 1. Melanose multicêntrica em frango de corte. A) carcaça de frango de corte com áreas multifocais enegrecidas na pele (ponta da seta), nas serosas dos intestinos delgado e grosso (setas) e no coração. B) áreas multifocais enegrecidas na moela (ponta da seta) e na pele. C) áreas multifocais enegrecidas na musculatura peitoral (seta). D) manchas enegrecidas multifocais a coalescentes em intensa quantidade no coração.

Ao exame microscópico, observou-se melanina multifocal variando de moderada a intensa quantidade em todos os órgãos acometidos com lesões enegrecidas na macroscopia. As Fig. 2A$\mathrm{D}$ demonstram essa pigmentação em intestino, coração, músculo peitoral e proventrículo. As áreas pigmentadas foram negativas para a coloração especial de azul da prússia, descartando a possibilidade de acúmulo de hemossiderina. Fígado, rins e baço não apresentaram pigmentação, e não foram encontradas células neoplásicas em nenhum dos tecidos avaliados. 

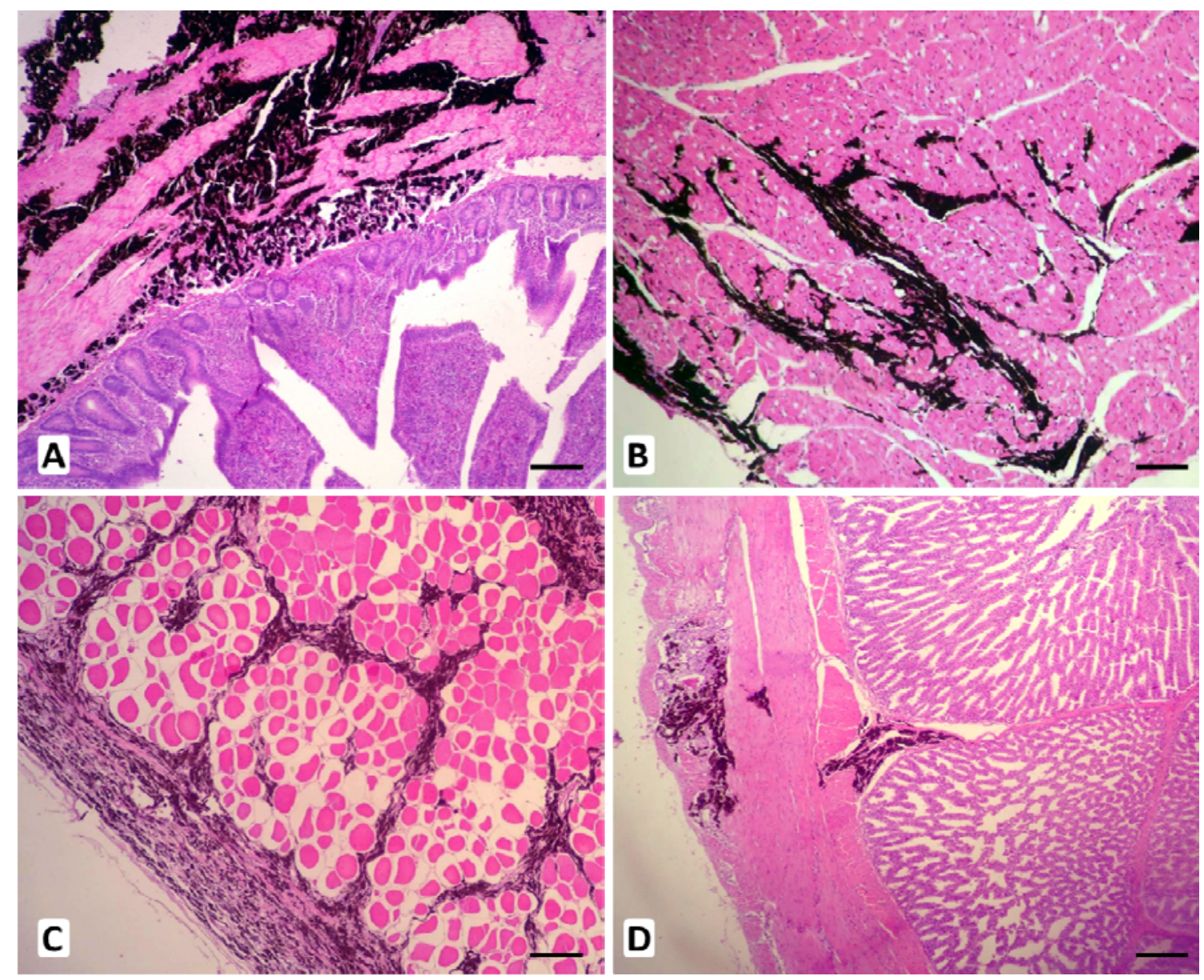

Figura 2. Melanose multicêntrica em frango de corte. A) intestino delgado com pigmentação em camadas submucosa e muscular. Hematoxilina e eosina, barra $=125 \mu \mathrm{m}$. B) músculo estriado cardíaco com pigmentação multifocal a coalescente. Hematoxilina e eosina, barra $=125 \mu \mathrm{m}$. C) músculo estriado esquelético com pigmentação multifocal a coalescente. Hematoxilina e eosina, barra $=125 \mu \mathrm{m}$. D) proventrículo com pigmentação multifocal. Hematoxilina e eosina, barra $=125 \mu \mathrm{m}$.

\section{DISCUSSÃO}

A pigmentação da pele em aves comercializadas no Ocidente é rara e, quando ocorre, é chamada de melanização dermal (Crespo e Pizarro, 2006) ou hiperpigmentação dermal (Dorshorst et al., 2011). A característica de pele clara é atribuída a uma mutação da PMEL17 introduzida nas linhagens comerciais para atender interesses econômicos (Hellström et al., 2011). Quando o acometimento ocorre em vísceras, a nomenclatura varia e os termos empregados incluem hiperpigmentação visceral, fibromelanose ou simplesmente melanose (Crespo e Pizarro, 2006; Arora et al., 2011).

No presente relato, foi diagnosticada melanose em pele, musculatura peitoral, bursa de
Fabricius, divertículo, serosas dos intestinos delgado e grosso, moela, inglúvio, proventrículo, pulmões e coração. Apesar de ser possível encontrar diversos trabalhos sobre as bases genéticas da pigmentação em aves naturalmente hiperpigmentadas (Dorshorst et al., 2011; Shinomiya et al., 2012), são poucos os trabalhos que discutem a melanose como causa de condenação em aves de linhagens comerciais não pigmentadas (Crespo e Pizarro, 2006), sendo ainda mais raro quando se trata de acometimento múltiplo dos órgãos. $\mathrm{Na}$ ampla literatura consultada, não foi verificado nenhum relato prévio de melanose multicêntrica em ave de linhagem comercial no Brasil. 
Em animais domésticos, especificamente os de corte, a melanose já foi relatada em bovinos, sendo os locais de maior acometimento a medula espinhal, a região pélvica, os pulmões, o coração, o fígado e o omento (Luján et al., 2009). Em suínos, os órgãos mais acometidos são glândula mamária, pulmões e pele (Teixeira et al., 2013). Há ainda relato de condenação de fígados de avestruzes (Mukaratirwa et al., 2009).

Existem diversos processos patológicos que podem desencadear quadros de hiperpigmentação, tais como distúrbios hormonais, doenças crônicas e neoplasias (Mcgavin e Zachary, 2007). Esses processos podem ser semelhantes macroscopicamente, apesar de distintos etiologicamente, tornando o diagnóstico por meio da inspeção visual muito difícil. Dessa forma, o ideal seria coletar material para análise histopatológica e posterior conclusão do diagnóstico (Teixeira et al., 2013).

Em estudo realizado por Teixeira et al. (2013), constatou-se que, em suínos de abate, existem lesões que podem ajudar a definir a etiologia do processo de pigmentação. Por exemplo, em casos de melanose, a região acometida não possui ulceração, enquanto um processo neoplásico tende a apresentar ulceração. Ainda assim, os autores destacam que se faz necessária uma abordagem ampla sobre o tema, com estudos envolvendo mais animais para gerar dados mais precisos.

Interessante notar que, ao passo que no Ocidente os consumidores rejeitam as aves pigmentadas, em países do Oriente existe preferência por esse tipo de animal (Crespo e Pizarro, 2006; Arora et al., 2011; Shinomiya et al., 2012). Supõe-se que tal preferência de consumo tenha base cultural, tendo em vista que na China, por exemplo, acredita-se que aves de carne escura possuem propriedades medicinais (Shinomiya et al., 2012).

Ainda não se sabe se a melanose pode afetar a taxa de crescimento e a qualidade da carne em aves naturalmente hiperpigmentadas (Arora et al., 2011), mas ao estudarem o efeito da pigmentação das penas de corujas, foi possível concluir que animais pigmentados são menos afetados por estresse e possuem taxa de crescimento maior. Supõe-se que tal fenômeno tenha base evolutiva e fisiológica, com participação do sistema melanocortina. A escolha da coruja nesse estudo foi baseada no fato de essa espécie ter diferentes intensidades de pigmentação entre os indivíduos e ainda pelo fato de se tratar de animais noturnos, então a melanina não teria papel principal de proteção contra radiação ultravioleta. Dessa forma, seria um bom modelo para avaliação de outros papéis físiológicos da pigmentação (Roulin e Ducrest, 2011). Considerando que a pigmentação de penas e pelos possui papel evolutivo e adaptativo (Roulin e Ducrest, 2011), pode-se supor que também exista algum papel fisiológico ou evolutivo nos frangos naturalmente hiperpigmentados, apesar de não terem sido encontrados trabalhos descrevendo tal papel. Assim, abre-se espaço para se desenvolverem pesquisas sobre a função dos diferentes graus de pigmentação existentes entre as diferentes aves domésticas de consumo humano, tendo em vista que muitas dessas diferenças ocorreram de forma natural e é plausível que possuam alguma base fisiológica e evolutiva.

Determinou-se que a hiperpigmentação de frangos é uma característica complexa, afetada por interações entre gene da fibromelanose (Fm) autossômico e genes Id ligados ao sexo (Arora et al., 2011). Alguns autores defendem a possibilidade de o fenótipo ser determinado por eventos que ocorrem na migração de melanócitos durante o desenvolvimento inicial (Shinomiya et al., 2012). O que se sabe é que, em espécies naturalmente hiperpigmentadas, a proliferação durante $\mathrm{o}$ desenvolvimento embrionário é acelerada e a migração dos melanoblastos é incomum (ventral). A proliferação acelerada é atribuída a uma alta exposição à endotelina vasoativa 3 (EDN3) antes $\mathrm{e}$ durante a diferenciação dos melanoblastos da crista neural. EDN3 é um gene ligado ao desenvolvimento de melanoblastos a partir da crista neural. Esse excesso de EDN3 em aves hiperpigmentadas é atribuído a uma duplicação de gene Fm detectada em frangos Silky (Shinomiya et al., 2012).

Estudo realizado por Dorshorst et al. (2011) identificou duas regiões com duplicação no genoma de aves de genótipo FM (alelo dominante para fibromelanose). Em uma dessas áreas de duplicação, há uma sequência que codifica endotelina vasoativa 3 , revelando aumento da expressão desse gene em aves Silkie naturalmente pigmentadas. Em alguns 
indivíduos, observa-se aumento de EDN3 sem manifestação fenotípica de pigmentação intensa, confirmando que existem outros genes atuando no processo, tais como os genes Id ligados ao sexo (Arora et al., 2011; Dorshorst et al., 2011).

O mesmo rearranjo complexo foi encontrado em quatro raças diferentes, provenientes de quatro países diferentes (Silkie da China, Ayam Cemani da Indonésia, Black HMong do Vietnã e Svarthona da Suécia), indicando que um único evento de mutação deve estar envolvido no processo de pigmentação da pele. Acredita-se que as mudanças estruturais de genes contribuíram significativamente para a evolução dos diferentes fenótipos nas galinhas domésticas. Mesmo quando um rearranjo ocorre em um único locus, ele pode ter efeitos múltiplos por alterar diferentes vias genéticas (Dorshorst et al., 2011).

Seria interessante desenvolver testes moleculares capazes de detectar aves com genótipo que previne o estabelecimento de melanose, de forma a selecionar tais animais e eliminar aqueles com genética indesejada dos plantéis (Crespo e Pizarro, 2006). Entretanto, tal objetivo é difícil de ser alcançado porque o controle da melanogênese e da migração de melanócitos é realizado por diversos genes, entre eles genes com efeito pleiotrópico, e a manipulação de tais genes resultaria em mudanças fenotípicas em diversos locais e funções (Roulin e Ducrest, 2011). Apesar de as bases genéticas da pigmentação em frangos naturalmente hiperpigmentados estarem sendo desvendadas, pouco se sabe sobre quais mutações desencadeiam melanose nas linhagens selecionadas para não apresentar pigmentação. Mais estudos devem ser realizados, de forma a tentar esclarecer tais mecanismos, pois, desse modo, seria possível realizar uma seleção genética mais efetiva, reduzindo ainda mais as perdas econômicas.

\section{CONCLUSÃO}

A ave apresentou melanose multicêntrica e tal alteração não compromete a função dos órgãos acometidos nem representa risco para a saúde humana, no entanto, devido ao aspecto macroscópico, os órgãos que apresentam tal lesão foram condenados para consumo humano.

\section{REFERÊNCIAS}

ARORA, G.; MISHRA, S.K.; NAUTIYAL, B. et al. Genetics of hyperpigmentation associated with the Fibromelanosis gene (Fm) and analysis of growth and meat quality traits in crosses of native Indian Kadaknath chickens and non-indigenous breeds. $\mathrm{Br}$. Poult. Sci., v.52, p.675-685, 2011.

CRESPO, R.; PIZARRO, M. Skin and abdominal fascia melanization in broiler chickens. Avian Dis., v.50, p.309-311, 2006.

DORSHORST, B.; MOLIN, A.; RUBIN, C. et al. A complex genomic rearrangement involving the endothelin 3 locus causes dermal hyperpigmentation in the chicken. PLoS Genet., v.7, p.e1002412, 2011.

DUPIN, E.; LE DOUARIN, N.M. Development of melanocyte precursors from the vertebrate neural crest. Oncogene, v.22, p.3016-3023, 2003.

FARACO, C.D.; VAZ, S.A.S.; PÁSTOR, M.V.D. et al. Hyperpigmentation in the Silkie fowl correlates with abnormal migration of fate-restricted melanoblasts and loss of environmental barrier molecules. Dev. Dyn., v.220, p.212-225, 2001.

HELLSTRÖM, A.R.; WATT, B.; FARD, S.S. et al. Inactivation of Pmel alters melanosome shape but has only a subtle effect on visible pigmentation. PLoS Genet., v.7, p.e1002285, 2011

LUJÁN, S.H.; ANTÓN, C.; JARO, P. et al. Prevalence of melanosis in cattle slaughtered in Spain. Vet. Rec., v.164, p.722-723, 2009.

MCGAVIN, M.D.; ZACHARY, J.F. Pathologic basis of veterinary disease. 4.ed. Philadelphia: Mosby Elsevier, 2007. 1476p.

MUKARATIRWA, S.; DZOMA, B.M.; MATONGO, C.; NYAHUMA, M. Some causes of organ and carcass condemnations in ostriches slaughtered at the only ostrich abattoir in Zimbabwe from 1999-2005. Int. J. Poult. Sci., v.8, p.1096-1099, 2009.

ROULIN, A.; DUCREST, A. Association between melanism, physiology and behavior: a role for the melanocortin system. Eur. J. Pharmacol., v.660, p.226-233, 2011.

SHINOMIYA, A.; KAYASHIMA, Y.; KINOSHITA, $\mathrm{K}$. et al. Gene duplication of endothelin 3 is closely correlated with the hyperpigmentation of the internal organs (Fibromelanosis) in Silky chickens. Genetics, v.190, p.627-638, 2012.

TEIXEIRA, C.; PIRES, I.; FERREIRA, S.; VIEIRAPINTO, M. Lesões melanocíticas em suínos abatidos para consumo. Arq. Bras. Med. Vet. Zootec., v.65, p.783-791, 2013. 